ARTIGOS

\title{
AS COMPETÊNCIAS DOCENTES NA PERSPECTIVA DA GERAÇÃO Y: UMA INVESTIGAÇÃO ENTRE ESTUDANTES DO BACHARELADO EM ADMINISTRAÇÃO
}

\author{
TEACHER SKILLS UNDER THE PERSPECTIVE OF \\ Y GENERATION: AN INVESTIGATION AMONG \\ UNDERGRADUATE STUDENTS IN ADMINISTRATION
}

\section{LAS COMPETENCIAS DOCENTES EN LA PERSPECTIVA DE LA GENERACIÓN Y: UNA INVESTIGACIÓN ENTRE ESTUDIANTES DEL BACHILLERATO EN ADMINISTRACIÓN}

\section{RESUMO}

Valenna Cássia de Deus Graduada em Administração pela Universidade Federal do Pará. Atualmente é Analista na empresa Biopalma da Amazônia S/A. Belém - PA - BR. E-mail: <valennadedeus@hotmail. com $>$.

Carlos André Corrêa de Mattos

Doutor em Ciências Agrárias. Mestre em Gestão e Desenvolvimento Regional. Bacharel em Administração. Professor da Faculdade de Administração (FAAD) da Universidade Federal do Pará (UFPA). Belém - PA - BR. E-mail:<carlosacmattos@ hotmail.com>.

José Augusto Lacerda Fernandes Doutor em Desenvolvimento Sustentável. Mestre em Administração. professor efetivo, Adjunto A, do Instituto de Ciências Sociais Aplicadas (ICSA) da Universidade Federal do Pará (UFPA). Belém $P A$ - BR. E-mail: <lacerda. fernandes@gmail.com>.
O objetivo da pesquisa foi analisar as competências docentes na perspectiva dos estudantes do bacharelado em administração da Geração Y e, com isso, identificar as características dos bons professores. A pesquisa classificada como exploratória e descritiva, foi feita na cidade de Belém-Pa, Brasil, sob forma de levantamento, e contou com 210 entrevistados em amostra não probabilística por acessibilidade. $\mathrm{O}$ instrumento de pesquisa foi o questionário, desenvolvido por Nogueira, Casa Nova e Carvalho (2012), e os dados foram tratados com estatística descritiva e multivariada. Os resultados da análise fatorial revelaram quatro fatores que explicaram $67,12 \%$ da variância e foram denominados como competência interpessoal, profissional, de técnicas de ensino e tecnológica. A análise de clusters formou cinco agrupamentos diferenciados principalmente pela competência profissional. A conclusão do estudo mostra elevada expectativa dos estudantes e necessidade de múltiplas competências para que os docentes sejam considerados bons professores.

Palavras-chave: Ensino Superior. Geração Y. Docência. Aprendizagem. Análise Multivariada.

\begin{abstract}
The objective of this research was to analyze the teacher skills under the perspective of Y Generation students of the bachelor's degree in administration and, thus, identify the characteristics of good teachers. This research, exploratory and descriptive, was carried out in the City of Belém-Pa, Brazil, under the survey form, and included two hundred and
\end{abstract}


ten respondents in a non-probabilistic sample by accessibility. The research instrument was a questionnaire developed by Nogueira, Casa Nova, and Carvalho (2012), and the data were analyzed with descriptive and multivariate statistics. Results of factor analysis showed that interpersonal and professional competence, appropriate usage of educational and technological techniques are the factors that explain $67.12 \%$ of the variance. The cluster analysis formed five groups mainly differentiated by professional competence. The conclusion of the study shows high expectations of students and the need for multiple skills so that teachers are considered good teachers.

Keywords: Higher education. Y generation. Teaching. Learning. Multivariate analysis.

\section{RESUMEN}

El objetivo de la pesquisa fue analizar las competencias docentes en la perspectiva de los estudiantes del bachillerato en administración de la Generación Y, con el objetivo de identificar las características de los buenos profesores. La pesquisa clasificada como exploratoria y descriptiva, fue realizada en la ciudad de Belém-PA, Brasil, a través de levantamiento, y contó con 210 entrevistados en amuestra no probabilística por accesibilidad. El instrumento de pesquisa fue el cuestionario, desarrollado por Nogueira, Casa Nova e Carvalho (2012), y los datos fueron tratados como estadísticas descriptiva y multivariada. Los resultados del análisis factorial revelaron cuatro factores que explicarían $67,12 \%$ de la variancia y fueron denominados como competencia interpersonal, profesional, de técnicas de enseñanza y tecnológica. El análisis de clusters constituyó cinco agrupamientos diferenciados principalmente por la competencia profesional. La conclusión del estudio presenta elevada expectativa de los estudiantes y necesidades de múltiples competencias para que los docentes sean considerados buenos profesores.

Palabras-chave: Enseñanza Superior. Generación Y. Docencia. Aprendizaje. Análisis Multivariada.

\section{INTRODUÇÃO}

A geração Y chegou ao ensino superior com uma perspectiva diferente do paradigma da ação docente. Os ditos nativos digitais, também chamados por Lombardia (2008) e Lancaster e Sillman (2011) de geração Power Ranger, Milênio, GenNext, geração Google, Echo Boom, geração Tech, entre outros, são controversos até mesmo quanto ao período temporal de sua geração, uma vez que não há uma delimitação pacificamente aceita na literatura que marque os anos que limitam seu início, sendo, em geral, considerados desta geração os nascidos entre 1982 e 2000 (LANCASTER; STILLMAN, 2011).

Caracterizada por uma geração de crianças cheias de energia, alegres e seguras de si, ela marca uma sociedade preocupada com a segurança, que vivenciou vertiginosos avanços tecnológicos (LANCASTER; STILLMAN, 2011). Essa relação, em especial com a internet, possibilitou o contato com um fantástico acervo de dados e processos comunicacionais que levou seus nativos a uma constante busca por informações (AMUI, 2011). Oriundos de famílias com menor número de filhos e com pais e mães que trabalham, os nativos dessa geração tendem a ser impacientes (MARIN; LIMA; CASA NOVA, 2011), a buscar resultados de curto prazo e a se concentrar mais no resultado do que no processo. Típicos do mundo globalizado, são o resultado de uma sociedade interconectada, de características predominantemente urbana, com fronteiras pouco estabelecidas (LOMBARDIA, 2008; MULLER; DEWES, 2012).

Apesar de os primeiros representantes da geração Y já estarem formados, muitos ainda estão inseridos no contexto das instituições de ensino superior, convivendo com docentes e com estruturas institucionais concebidas por outras gerações, principalmente pela Geração X, representada pelos nascidos entre os anos de 1965 e 1981, ou mesmo os Baby Boomers do período de 1946 a 1964 (LANCASTER; STILLMAN, 2011), para os quais as tecnologias não eram tão acessíveis e disponíveis, fato que transformou essas gerações em imigrantes tecnológicos.

Entender as diferenças entre gerações, ganha destaque na perspectiva das instituições de 
ensino pela necessidade de encontrarem novas formas de relacionamento e organização. Nesse sentido, os nativos da Geração Y, foram os primeiros a chegar às instituições de ensino e ao mercado de trabalho com tamanha proximidade com os recursos tecnológicos. Assim, Nogueira, Casa Nova e Carvalho (2012) destacam que esse gap tecnológico apresentou reflexos nas relações entre estudantes e docentes e que a aceleração da chegada de indivíduos cada vez mais novos ao ensino superior tende a aumentar esse impacto.

Dessa forma, para contribuir com o entendimento das competências docentes esperadas pelos estudantes de Administração da geração Y e com isso trazer informações que possam contribuir para melhores práticas docentes e institucionais, o problema de pesquisa que motivou este estudo foi: quais as competências docentes mais valorizadas pelos estudantes do bacharelado em Administração da Geração Y capazes de diferenciar os bons professores?

Tendo como referência esse questionamento, a investigação se concentrou no objetivo de analisar as capacidades dos professores, que são destacadas pelos nativos digitais como distintivas dos bons professores. Para tanto, o artigo se estruturou fundamentado na compreensão de competência e, em especial, nas competências docentes, sendo realizada a pesquisa de campo com tratamento de dados quantitativos para sistematizar as opiniões dos entrevistados.

\section{COMPETÊNCIAS: ORIGEM, EVOLU- ÇÃO E APLICAÇÕES}

O termo competência tem origem no latim competentia e existe desde a idade média associado à linguagem jurídica, na qual é empregado para designar a faculdade para julgar (CHAUI, 2003). Utilizado até os dias atuais, a expressão competência indica, essencialmente, a capacidade de opinar a respeito de determinado tema. $\mathrm{Na}$ administração pública, competência pode ser compreendida como o poder atribuído ao agente público para o desempenho de suas funções (GOMES; MORGADO, 2012). Desde a Revolução Industrial, a expressão competência era utilizada para qualificar os trabalhadores aptos a executar as tarefas (CARDOSO, 2009). Dessa diversidade de utilizações, observa- -se a amplitude histórico-temporal da expressão competência e destaca-se que a incompetência, seu antônimo, supera a compreensão da negação de capacidade para assumir uma compreensão pejorativa (FLEURY, M.; FLEURY, A., 2001).

A compreensão contemporânea de competência, no âmbito organizacional, foi concebida no final da década de 1980 e constituída por duas perspectivas teóricas e conceituais distintas, uma de origem norte-americana e outra francesa, ambas desenvolvidas concomitantemente. A perspectiva norte-americana entende a competência associada ao conjunto de conhecimentos, habilidades e atitudes do indivíduo. A perspectiva francesa concebe competência como a ação do indivíduo ao enfrentar situações e sua iniciativa para assumir responsabilidades em ambientes profissionais (ZARAFIAN, 2003). As competências se materializam pela articulação de múltiplas habilidades, combinadas e constituídas em ambientes complexos, imprevisíveis e em permanente estado de transformação (SOUZA; ZAMBALDE, 2015).

Nesse contexto, competência pode ser compreendida tanto como um conjunto de conhecimentos, habilidades e atitudes, que, presentes no indivíduo, o qualificam para realizar determinadas tarefas (DUTRA; HIPÓLITO; SILVA, 2000; PICCHIAI, 2009; DIAS JÚNIOR et al., 2014), quanto como uma vinculação ao senso de responsabilidade, que leva o indivíduo a ter iniciativa para enfrentar situações presentes em seu dia a dia profissional (ZARAFIAN, 2003). Assim, a competência, para se constituir de fato, necessita da combinação sinérgica de aprendizagens sociais e de comunicação, que poderão resultar na realização eficiente da mobilização, integração e transferência de recursos e habilidades pessoais em prol de determinado cenário profissional e social (PICCHIAI, 2009). Amaro (2008) reforça essa compreensão ao destacar que a competência é constituída pela combinação de saberes e vontades individuais representados pelos recursos do indivíduo, que, ao serem combinados na busca por objetivos pessoais ou profissionais, se materializam na forma de desempenho. A noção de competência nessa concepção associa-se eminentemente à ação e a resultados (PINHEL; KURCGANT, 2007) e a mobilização (RUAS, 2005). 
Na perspectiva norte-americana, o indivíduo competente é aquele que reúne os conhecimentos, compreendidos pelo saber, com habilidades, materializadas pelas práticas, que, ao serem combinadas com comportamentos ou atitudes baseadas na vontade e disposição para fazer, agir, entregar e realizar, resultam em competências. Assim, a atitude representa o querer fazer. Portanto, aquele que é tido como competente está apto a alcançar o desempenho esperado, uma vez que dispõe dos elementos pessoais necessários para tal (DIAS JÚNIOR et al., 2014).

Dutra, Hipólito e Silva (2000) destacam que a literatura norte-americana reforça a busca pelo alto desempenho quando se trata de competência. Dessa forma, é necessária a mobilização de um conjunto de qualificações individuais para que se possa realizar um trabalho com a performance almejada. O trabalho, assim, é como um prolongamento das competências que o indivíduo mobiliza em face de uma situação profissional cada vez mais mutável e complexa. Os conhecimentos e o saber fazer somente adquirem status de competência se comunicados e utilizados. A rede de conhecimento em que se insere o indivíduo é fundamental para uma comunicação eficiente que promova competências (PICCHIAI, 2009).

As competências são essencialmente individuais, coletivas e organizacionais. Michaux (2011), ao se referir à evolução dos estudos sobre competências individuais, reforça que sua relevância se fortalece na gestão de pessoas a partir da década de 1980. Por outro lado, ao se referir às competências coletivas, ele destaca que elas foram originalmente estudadas pela psicologia e assumiram relevância na Administração a partir das décadas de 1990 e 2000 . O autor reforça que, apesar de operacionalmente os conceitos de competências individuais e coletivas não estarem obrigatoriamente vinculados à compreensão com o advento da teoria dos sistemas, foi sedimentada a compreensão de que as competências organizacionais emergem das competências coletivas, que, por sua vez, são o resultado do somatório de competências individuais. Assim, a compreensão de competência ultrapassa naturalmente o caráter individual, constituindo elemento de destaque, tanto na pers- pectiva coletiva, quanto organizacional (BRUNO-FARIA; BRANDÃO, 2003; SILVA, 2012).

Gomes e Morgado (2012) complementam, ao afirmar que as competências organizacionais envolvem competências de ordem estratégica, como as competências essenciais e as competências distintivas, ambas relacionadas à formação e manutenção de vantagens competitivas sustentáveis (BARNEY; HESTERLY, 2007). Grimand (2011), por sua vez, reforça que, em determinadas situações, as competências individuais são tão raras e necessárias para a criação de valor que passam a representar uma competência estratégica. Essa situação ocorre especialmente em organizações com equipes altamente especializadas em segmentos muito dependentes da qualificação de seus trabalhadores para competir e prosperar.

Ao se referir às competências coletivas, Silva (2012) destaca que, apesar da falta de um consenso pacificamente aceito para seu significado, a cooperação é considerada um fator crucial para que ela possa se constituir de fato e trazer benefícios organizacionais. Essa perspectiva cognitiva das competências coletivas é reforçada por Michaux (2011) ao se referir à forma como a rotina e o processo de aprendizagem são internalizados nas equipes de trabalho. Assim, as rotinas operacionais, além de reprimirem atitudes oportunistas, transmitem um padrão de comportamento aceitável na organização, que, por serem únicos e por reunirem aspectos formais e elementos tácitos, tipificam a organização e dificilmente serão reproduzidos ou imitáveis em ambientes organizacionais distintos. Esse conjunto de elementos pode ser compreendido como a forma que conduz um grupo de pessoas para alcançar determinado objetivo, podendo ocorrer com maior facilidade em ambientes propícios à interação entre seus integrantes (BONOTTO; BITENCOURT, 2006).

Dessa forma, para que as competências individuais influenciem o desempenho da organização, é necessário que ocorra um processo de aprendizagem e que posteriormente os indivíduos compartilhem seus conhecimentos e os transformem em preceitos para suas ações (FLEURY, M.; FLEURY, A., 2001). Nessa conjuntura, inserem-se as estratégias organizacionais como norteadoras dessa aprendi- 
zagem (SILVA, 2012). O conceito de competência ganhou destaque nas pesquisas acadêmicas e nos ambientes organizacionais em virtude de sua participação no atendimento das necessidades individuais, organizacionais e sociais, especialmente no que se refere à capacidade de atuar frente a imprevistos, em processos de comunicação e articulação pessoal e na compreensão de si e dos outros.

Todavia, é necessário refletir sobre a formação individual dos profissionais de Administração em face do desenvolvimento das competências necessárias ao exercício da profissão, pois somente assim, serão mitigados os impactos negativos de cenários sistêmicos, complexos, incertos e descontínuos (CLOSS; ARAMBURU; ANTUNES, 2009). Assim, na formação dos administradores, inserem-se os docentes, destacados como mediadores do processo de aprendizagem e formação profissional do estudante (LIBÂNEO, 2013).

No ambiente educacional, a competência docente constitui-se como o elo no agir sustentado em conhecimentos específicos da profissão. Contudo, não se limita a eles, por exigir que os docentes utilizem vários recursos cognitivos combinados de forma integrada para serem eficazes nas situações vivenciadas no ambiente acadêmico. Destaca-se que a compreensão de competência na formação profissional dos estudantes substituiu a compreensão de qualificação empregada no passado pela necessidade de articular múltiplas formas de agir e articular capacidades profissionais (PINHEL; KURGANT, 2007).

\section{COMPETÊNCIAS DOCENTES: INSERÇÃO E EXPECTATIVAS}

Compreender as competências necessárias ao exercício da docência e, mais que isso, reunir os elementos que singularizam os bons professores é uma preocupação de diversos estudos contemporâneos (NOGUEIRA; CASA NOVA; CARVALHO, 2012; ORO; SANTANA; RAUSCH, 2013; CANDIDO et al., 2014; GUELFI et al., 2015). Martins e Rauch (2012) destacam que a docência universitária precisa ser constantemente questionada para possibilitar o aprimoramento de suas práticas e configurações. Nessa perspectiva, investigar as competências docentes assume posição central nas pesquisas, uma vez que os professores representam um dos principais elos entre os estudantes e as instituições.

Guedes, Andrade e Nicolini (2015) reforçam que o mercado de trabalho moderno exige profissionais hábeis na solução de problemas, capazes de atuar em equipe, orientados por comportamentos éticos e cientes das exigências de cidadania. Os autores destacam que a formação desses profissionais exige mais dos professores e das instituições de ensino. Esse aspecto implica novas metodologias que privilegiem um caráter inovador na educação e que sejam capazes de deslocar o estudante de uma posição passiva, para ser o principal responsável por seu desenvolvimento pessoal.

A formação profissional para o mercado de trabalho, nessas condições, passa necessariamente pelo aprimoramento de competências. Nesse contexto, a expressão competência e seus vários significados revelam um construto de características polissêmicas e transversais, que se estendem desde o campo organizacional ao estudantil, destacando-se pela capacidade de aplicar na prática conhecimentos teóricos e tendo no seu cerne a ação do indivíduo para realizá-la (PINHEL; KURCGANT, 2007).

A conceituação de competência docente fundamentada no conjunto de conhecimentos, habilidades e atitudes é criticada por Nóvoa (2009) que, mesmo considerando as contribuições das últimas décadas, avalia que a expressão competência não perdeu seu caráter comportamentalista e técnico-instrumental. Entretanto, a expressão competência docente ainda é a principal referência em muitos estudos atuais sobre a temática, sendo encontrada em diversas pesquisas para identificar qualidades necessárias aos bons professores (PINHEL; KURCGANT, 2007; PAIVA; MELO, 2009; NOGUEIRA; BASTOS, 2012; SOUZA; ZAMBALDE, 2015). Portanto, independentemente do ponto de vista dos pesquisadores, um aspecto parece pacífico, os bons professores são aqueles que apresentam na relação com o estudante e em suas práticas laborais algumas características capazes de distingui-los dos demais professores.

Nesse sentido, os professores, como destacado por Paiva e Melo (2009), via de regra, assumem em grande parte o desenvolvimento de suas competências individuais, uma vez que, de manei- 
ra geral, as políticas de gestão de pessoas das instituições de ensino falham nesse aspecto, ou não conseguem convencer os professores de sua eficácia. Constatação semelhante foi identificada por Hanashiro e Nassif (2006), que observaram nos estudos realizados acerca das competências docentes que as instituições federais de ensino não estimulam seu desenvolvimento com ações práticas.

Nessa perspectiva, o conhecimento técnico profissional, apesar de essencial, não é o suficiente para o professor universitário, mesmo considerando tratar-se de uma das características mais valorizadas pelos estudantes (PLUTARCO; CRADVOHL, 2010). Assim, o conhecimento técnico profissional precisa ser complementado pela dimensão didática, que deve ser capaz de privilegiar uma abordagem formativa mais ampla para o estudante (PIMENTA; ANASTASIOU, 2014). Essa compreensão é reforçada por Masetto (2003) ao criticar que a titulação acadêmica do professor e sua experiência profissional são apenas algumas das exigências necessárias ao magistério universitário, que devem ser complementadas pela competência pedagógica.

Quanto às competências necessárias aos professores, destacam-se aspectos como a necessidade de comunicação para facilitar a compreensão, o processo de aprendizado constante necessário para manter o professor em permanente aprimoramento profissional e a capacidade de assumir responsabilidades, representada pelo comprometimento com as dificuldades dos estudantes na mediação da aprendizagem (KARAWEJCZYK; ESTIVALETE, 2003). Dessa forma, em certa medida, o docente se torna "responsável por conduzir o processo de aprendizagem." (SANTOS, 2013, p. 36).

Observa-se que, de maneira geral, Quadro 1, os estudos reforçam que as competências necessárias aos professores se estruturam com base em um amplo conjunto de capacidades, que incluem preparar boas aulas e transmiti-las com clareza, de tal forma a facilitar a compreensão, o que os estudantes classificam como a didática do professor. Conhecimento e experiência profissional são aspectos valorizados por possibilitarem a compreensão da prática profissional. Além da capacidade de desenvolver bons relacionamentos interpessoais, mostrando-se sensível às necessidades dos estudantes, com aulas dinâmicas, receptivos e bem-humorado, os bons professores incentivam a participação dos estudantes, são exigentes e revelam a capacidade de se envolver com o resultado do aprendizado, mantendo-se atualizados quanto aos acontecimentos e mudanças na profissão. Esses resultados revelam que as expectativas quanto ao trabalho docente são elevadas quando compreendidas pela ótica do estudante.

Quadro 1 - Competências necessárias aos docentes universitários

\begin{tabular}{|l|l|}
\hline \multicolumn{1}{|c|}{ Autor } & \multicolumn{1}{|c|}{ Competências } \\
\hline Cunha (2017) & $\begin{array}{l}\text { (1) acreditar no potencial dos estudantes; (2) ser exigente; (3) ter domínio do } \\
\text { conteúdo ensinado; (4) desenvolver bons relacionamentos; (5) ser incentivador da } \\
\text { participação discente; (6) manter a aula agradável; e (7) ser bem-humorado. }\end{array}$ \\
\hline Nóvoa (2009) & $\begin{array}{l}\text { (1) conhecimento; (2) cultura profissional; (3) ser pedagógico; (4) trabalhar em } \\
\text { equipe; e (5) ter compromisso social. }\end{array}$ \\
\hline Paiva e Melo (2009) & $\begin{array}{l}\text { (1) competências cognitivas; (2) competências funcionais; (3) competências } \\
\text { comportamentais; (4) competências éticas; e (5) competências políticas. }\end{array}$ \\
\hline Plutarco e Gradvohl (2010) & $\begin{array}{l}\text { (1) didática; (2) conhecimento teórico; (3) experiência de mercado; (4) } \\
\text { relacionamento; e 5) ser exigente. }\end{array}$ \\
\hline Pachane (2012) & $\begin{array}{l}\text { (1) didática; (2) desenvolver bom relacionamento pessoal; (3) domínio do } \\
\text { conteúdo; (4) habilidades de comunicação; e (5) preocupação com a aprendizagem. }\end{array}$ \\
\hline Candido et al. (2014) & $\begin{array}{l}\text { (1) didática; (2) bom relacionamento interpessoal; (3) preocupação com o futuro } \\
\text { do estudante; (4) ser motivado; (5) ter conhecimento técnico; (6) compromisso e } \\
\text { profissionalismo; e (7) ser atualizado. }\end{array}$ \\
\hline
\end{tabular}

Fonte: pesquisa de campo. 


\section{METODOLOGIA}

A metodologia utilizada nesta pesquisa, consoante a taxonomia de Martins e Theóphilo (2009), caracteriza-se como uma investigação exploratória e descritiva, feita na forma de levantamento transversal, com amostragem não probabilística por acessibilidade e tratamento de dados quantitativos. Essa forma de pesquisa é estruturada por uma investigação inicial, para possibilitar a compreensão ampla do fenômeno, fase exploratória, seguida da caracterização de seus aspectos principais, fase descritiva, assim se pretende possibilitar sua compreensão. Esse conjunto de procedimentos contribui para revelar aspectos do objeto de estudo. A técnica de amostragem utilizada neste levantamento não permite controlar o erro amostral (HILL, M.; HILL, A., 2012). Ao final do trabalho de campo, foram obtidos 210 questionários de pesquisas válidos, respondidos por estudantes do curso de bacharelado em Administração.

O instrumento de coleta de dados foi o questionário, desenvolvido por Nogueira, Casa Nova e Carvalho (2012) em duas seções. A primeira, foi formada por questões dicotômicas e de múltipla escolha, que teve por finalidade caracterizar o entrevistado quanto a seus aspectos socioeconômicos. A segunda, em escala intervalar de Likert, com 10 opções de respostas, estendendo-se em intensidade entre 1 para discordo totalmente, até 10 para concordo totalmente, reuniu características pessoais e aspectos da prática docente, selecionados por seus autores por sua capacidade para distinguir bons professores.

O tratamento dos dados utilizou técnicas quantitativas, especificamente, técnicas de estatísticas descritivas e multivariadas: (1) quanto às técnicas descritivas, foram empregados a distribuição de frequência, a média e o desvio padrão, tendo esses procedimentos sido utilizados para a caracterização dos entrevistados e identificação dos agrupamentos; (2) quanto às técnicas multivariadas, foram selecionadas a análise fatorial exploratória (AFE) e a análise de clusters (AC).

A análise fatorial foi escolhida pela capacidade de sumarizar grande volume de informações em reduzido número de fatores, com isso, possibilitando identificar variáveis latentes. A Análise de Clusters privilegiou a investigação pela possibilidade de reunir os entrevistados mais semelhantes entre si e, com isso, classificá-los, quantificá-los e organizá-los em grupos. Esse conjunto de procedimentos de análise de dados visou, inicialmente, a identificar os fatores distintivos dos bons professores e, posteriormente, a observar como os entrevistados se organizavam quanto às competências identificadas. Os procedimentos multivariados foram feitos em consonância com Pestana e Gageiro (2008), Fávero et al. (2009) e Hair Junior et al. (2009).

Os questionários de pesquisa incluíram o Termo de Consentimento Livre e Esclarecido (TCLE), conforme os padrões éticos de pesquisa com seres humanos, e tiveram a fidedignidade mensurada pelo coeficiente alpha de Cronbach, que foi utilizado, tanto para as variáveis em conjunto, quanto para os fatores isolados, revelando boa consistência interna, uma vez que o coeficiente foi maior a 0,757 , superior ao valor recomendado por Kline (1998), Hair Junior et al. (2009) e Costa (2011), que consideram alfas acima de 0,600 e 0,700 satisfatórios para estudos exploratórios.

\section{APRESENTAÇÃO E DISCUSSÃO DE RESULTADOS}

Os estudantes que participaram da pesquisa foram oriundos de duas universidades da Região Metropolitana de Belém do Pará: 82,4\% (173) eram alunos da Universidade Federal do Pará- UFPA e 17,61\% (37), da Universidade da Amazônia UNAMA. Já com relação ao gênero, a amostra foi composta por $50 \%$ (105) de estudantes do sexo masculino e $50 \%$ (105) do sexo feminino. Quanto ao período de realização do curso, a amostra foi bem distribuída entre os períodos, com leve predominância do terceiro e quarto ano, com, respectivamente, $32,85 \%$ (69) e $28,10 \%$ (59) dos estudantes posicionados nesses estratos. Já com relação à data de nascimento, todos foram da Geração Y, com 39,05\% (82) nascidos entre 1982 e 1991 e 60,95\% (128), entre 1992 e 1998 (LANCASTER; STILLMAN, 2011). Assim, o estudante mais novo a participar da pesquisa tinha 18 anos e o mais velho 34 anos. Destacou-se que a maioria dos entrevistados exercia alguma atividade além da universidade, sendo que $71,43 \%$ (150) ou trabalhava ou fazia estágio. 
A análise descritiva das variáveis, Tabela 1, revelou médias elevadas para as variáveis em estudo, uma vez que todas foram superiores a 7,88. A opção pelos estratos superiores da escala de Likert ( 1 a 10) mostra que os entrevistados consideraram as variáveis relevantes no processo ensino-aprendizagem. Outra característica foi a baixa dispersão dos dados, com coeficiente de variação (CV) inferior a 23,77\% para todas as variáveis. Destacaram-se pelas maiores médias, todas acima de 9,00, a capacidade do

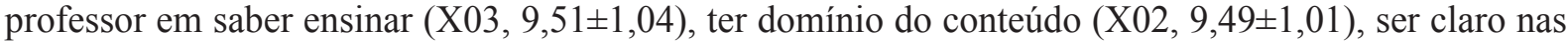

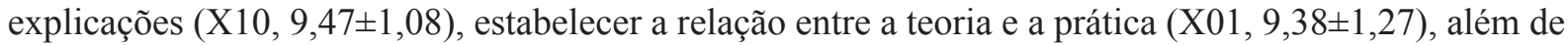
preparar bem o material didático (X11, 9,18 $\pm 1,23)$, conseguir despertar o interesse (X04, 9,06 $\pm 1,36)$ e preparar-se para as aulas $(\mathrm{X} 12,9,05 \pm 1,48)$. Muitos desses aspectos convergem com Madeira (2010) ao destacar os atributos de um bom professor na perspectiva dos estudantes.

Tabela 1 - Análise descritiva

\begin{tabular}{l|c|c|c|c|c|c}
\hline \multicolumn{1}{c|}{ Variáveis } & & Min. & Max. & Média & DP & CV (\%) \\
\hline Saber fazer a ligação entre a teoria e a prática & $\mathrm{X} 01$ & 1 & 10 & 9,38 & 1,27 & 13,54 \\
\hline Ter domínio do conteúdo que está ensinando & $\mathrm{X} 02$ & 5 & 10 & 9,49 & 1,01 & 10,64 \\
\hline Capacidade de explicar (didático) & $\mathrm{X} 03$ & 5 & 10 & 9,51 & 1,04 & 10,93 \\
\hline Despertar o interesse do aluno pelo conteúdo & $\mathrm{X} 04$ & 1 & 10 & 9,06 & 1,36 & 15,01 \\
\hline Ser atencioso com os alunos & $\mathrm{X} 05$ & 1 & 10 & 8,62 & 1,58 & 18,32 \\
\hline Ser acessível aos alunos & $\mathrm{X} 06$ & 4 & 10 & 8,79 & 1,42 & 16,15 \\
\hline Ser amigável com os alunos & $\mathrm{X} 07$ & 1 & 10 & 7,98 & 1,88 & 23,55 \\
\hline Ser compreensivo com os alunos & $\mathrm{X} 08$ & 1 & 10 & 8,57 & 1,56 & 18,20 \\
\hline Ser simpático com os alunos & $\mathrm{X} 09$ & 1 & 10 & 7,88 & 1,75 & 22,21 \\
\hline Ser claro nas explicações & $\mathrm{X} 10$ & 4 & 10 & 9,47 & 1,08 & 11,40 \\
\hline Preparar bem o material utilizado nas aulas & $\mathrm{X} 11$ & 3 & 10 & 9,18 & 1,23 & 13,40 \\
\hline Vir preparado para as aulas (conteúdo) & $\mathrm{X} 12$ & 1 & 10 & 9,05 & 1,48 & 16,35 \\
\hline Ser organizado & $\mathrm{X} 13$ & 2 & 10 & 8,80 & 1,53 & 17,38 \\
\hline Utilizar internet (sites, artigos, materiais etc.) & $\mathrm{X} 14$ & 1 & 10 & 7,95 & 1,89 & 23,77 \\
\hline Utilizar e-mail para se comunicar (alunos) & $\mathrm{X} 15$ & 1 & 10 & 8,39 & 1,77 & 21,09 \\
\hline
\end{tabular}

Legenda: Min.=mínimo; Max.=Máximo; DP=Desvio Padrão; $C V=$ Coeficiente de Variação;

Fonte: pesquisa de campo.

A análise da matriz de dados mostrou-se adequada à utilização da análise fatorial exploratória (AFE). A quantidade de correlações médias e altas significativas, a determinante da matriz diferente de zero $(0,002)$, a relação entre o número de variáveis e o de observações (15 observações por variável) e os testes $\operatorname{KMO}(0,803)$ e o de esfericidade de Bartllet (significativo a $1 \%$ ), confirmaram o bom ajustamento à técnica. Dessa forma, foi feita a extração dos fatores, que ocorreu pelo critério do autovalor; assim, cada fator explicou minimamente a própria variância (HAIR JUNIOR et al., 2009).

Os fatores foram extraídos pelo método de análise dos componentes principais (ACP) com rotação ortogonal Varimax (Tabela 02). Após a rotação, foram identificados quatro fatores que explicaram $67,12 \%$ da variância dos dados, cada fator explicou, respectivamente, $22,15 \%, 17,28 \%$ $16,30 \%$ e 11,39\% das variâncias em ordem decrescente do primeiro para o quarto fator. A comunalidade das variáveis se posicionou acima de 0,528 para todas as variáveis em estudo, mostrando que, pelo menos 52,8\% da variância das variáveis, foi explicada pelos fatores. O coeficiente alpha de Cronbach de 0,852 para todas as variáveis em conjunto e de 0,873 (Fator 1), 0,777 (Fator 2), 0,757 (Fator 3) e 0,797 (Fator 4) revelou boa consistência interna, tanto das variáveis em conjunto, quanto dos fatores individualmente todos adequados, segundo Costa (2011), Hair Junior et al. (2009) e Kline (1998). 
O primeiro fator reuniu cinco variáveis (X07, X09, X08, X05 e X06) e foi denominado como “Competências Interpessoais" pela capacidade de desenvolver relacionamentos amigáveis, construtivos e harmoniosos com os estudantes. O segundo fator concentrou quatro variáveis (X01, X03, X04 e X02) e foi denominado como "Competências Profissionais", uma vez que captou aspectos da experiência profissional do professor e sua habilidade de estabelecer relações entre a teoria e a prática da profissão. O terceiro fator reuniu quatro variáveis (X11, X12, X13, X10), sendo denominado como "Competências Técnicas de Ensino", pois captou aspectos do cotidiano do professor e sua prática na condução da disciplina. O quarto fator reuniu duas variáveis (X15 e X14) e foi denominado como "Competências Tecnológicas" por incluir a utilização da tecnologia no cotidiano da relação com os estudantes.

Tabela 2 - Fatores, variáveis, cargas fatoriais, comunalidade e Alphas de Cronbach

\begin{tabular}{|c|c|c|c|c|c|c|}
\hline \multirow{2}{*}{\multicolumn{2}{|c|}{ Variáveis }} & \multicolumn{4}{|c|}{ Fatores } & \multirow{3}{*}{$\begin{array}{c}\text { h2 } \\
0,760\end{array}$} \\
\hline & & \multirow{2}{*}{$\begin{array}{c}1 \\
0,849\end{array}$} & \multirow{2}{*}{$\begin{array}{c}\mathbf{2} \\
0,003\end{array}$} & \multirow{2}{*}{$\begin{array}{c}\mathbf{3} \\
0,175\end{array}$} & \multirow{2}{*}{$\begin{array}{c}4 \\
0,091\end{array}$} & \\
\hline Ser amigável com os alunos & $\mathrm{X} 07$ & & & & & \\
\hline Ser simpático com os alunos & X09 & 0,838 & 0,044 & 0,030 & 0,150 & 0,728 \\
\hline Ser compreensivo com os alunos & X08 & 0,799 & 0,151 & 0,073 & 0,206 & 0,709 \\
\hline Ser atencioso com os alunos & X05 & 0,732 & 0,187 & 0,188 & 0,097 & 0,616 \\
\hline Ser acessível aos alunos & X06 & 0,671 & 0,282 & 0,295 & $-0,024$ & 0,617 \\
\hline Saber fazer a ligação entre a teoria e a prática & $\mathrm{X} 01$ & 0,191 & 0,793 & $-0,072$ & $-0,068$ & 0,675 \\
\hline Capacidade de explicar (didático) & $\mathrm{X} 03$ & 0,037 & 0,792 & 0,220 & 0,042 & 0,679 \\
\hline Despertar o interesse dos alunos pelo conteúdo & X04 & 0,075 & 0,756 & 0,134 & 0,086 & 0,602 \\
\hline Ter domínio do conteúdo que está ensinando & $\mathrm{X} 02$ & 0,158 & 0,693 & 0,108 & 0,106 & 0,528 \\
\hline Preparar bem o material utilizado nas aulas & $\mathrm{X} 11$ & 0,071 & 0,185 & 0,826 & 0,027 & 0,722 \\
\hline Vir preparado para as aulas (conteúdo) & $\mathrm{X} 12$ & 0,231 & $-0,027$ & 0,779 & $-0,023$ & 0,662 \\
\hline Ser organizado & $\mathrm{X} 13$ & 0,281 & 0,021 & 0,679 & 0,061 & 0,544 \\
\hline Ser claro nas explicações & $\mathrm{X} 10$ & $-0,003$ & 0,306 & 0,661 & 0,209 & 0,574 \\
\hline Utilizar e-mail para se comunicar (alunos) & $\mathrm{X} 15$ & 0,157 & 0,011 & 0,122 & 0,882 & 0,818 \\
\hline Utilizar a internet (sites, artigos, artigos, etc.) & $\mathrm{X} 14$ & 0,207 & 0,123 & 0,040 & 0,880 & 0,833 \\
\hline Autovalores & & 3,32 & 2,59 & 2,44 & 1,71 & 10,06 \\
\hline Variância explicada (\%) & & 22,15 & 17,28 & 16,30 & 11,39 & 67,12 \\
\hline Alpha de Cronbach & & 0,873 & 0,777 & 0,757 & 0,797 & 0,852 \\
\hline
\end{tabular}

$\mathrm{KMO}=0,803$; Teste de Esfericidade de Bartllet $(\chi 2)=1.241,44$, significante a $1 \%$.

Forma de extração dos fatores ACP com rotação ortogonal pelo método Varimax

Determinação do número de fatores pelo critério do autovalor

Fonte: pesquisa de campo

O fator "Competência Interpessoal" captou a valorização dos estudantes quanto à aprendizagem estruturada por relações construtivas, materializadas na atenção do professor no ambiente acadêmico. Essencialmente, refere-se ao fortalecimento da integração professor e aluno para favorecer a construção do conhecimento de forma produtiva. Estabelecida por ações proativas de caráter mais pessoal, baseia-se na relação amigável e atenciosa do professor. Perspectivas semelhan- tes estão presentes nos estudos de Cunha (2017), Paiva e Melo (2009), Plutarco e Gradvohl (2010), entre outros.

A "Competência Interpessoal" se fundamenta nas dificuldades enfrentadas pelos estudantes e na sensibilidade para compreendê-las e, com isso, buscar superá-las de forma colaborativa. Essas características facilitam a comunicação e contribuem para que ocorra a aproximação dos estudantes com o professor e propiciem um am- 
biente acessível fundamentado em relações menos impessoais.

Pimenta e Anastasiou (2014), ao referir-se aos estudantes que chegam ao ensino superior, destacam que, no ensino médio, na maioria das vezes, a aprendizagem se sustenta na memorização dos conteúdos, em salas de aula com numerosos estudantes, em processos pouco participativos, nos quais a preocupação básica é o ingresso na universidade. Esse processo resulta em baixa capacidade crítica, o que faz com os estudantes, em certa medida, reproduzam essa compreensão no ensino superior. Nesse processo, quando a lógica se desloca para a formação e o exercício da profissão, as pressões presentes no cotidiano dos cursos universitários podem desencadear nos estudantes a necessidade de maior aproximação do professor para superar as lacunas trazidas do ensino médio e fortalecer a compreensão dos aspectos profissionais.

Por outro lado, Cândido et al. (2014), Cunha (2017) e Madeira (2010) reforçam que os estudantes valorizam o lado humano do professor, que Madeira (2010) classifica como perfil humanista, valorizando a amizade, a capacidade de construção de bons relacionamentos, a criatividade, a sabedoria, a modernidade e a capacidade motivadora. Nessa perspectiva, reforça competências voltadas para aspectos da relação interpessoal, identificadas nesse fator. Complementando essa perspectiva, Cunha (2017) reforça que as práticas do professor se materializam considerando seus objetivos, seja de internalizar, ou de conscientizar. E nesse processo, o distanciamento e a proximidade revelam-se práticas de uma mesma perspectiva.

Contudo, não se pode retirar da análise a compreensão de que o professor universitário também é resultado de um processo formativo, que, muitas vezes, privilegiou apenas aspectos técnicos da profissão (MADEIRA, 2010; CUNHA, 2017). Isso se associa a uma ampla conjuntura de fatores que, de certa forma, contribuem para um relativo distanciamento dos estudantes, como a carga horária de trabalho, a quantidade de turmas, condições de trabalho, burocracia, entre outras (TARDIF; LESSARD, 2008), que são o resultado de modelos produtivistas que, progressivamente, se instalaram nas universidades (ALCADIPANI; BRESLER, 2000). Essas questões, com intensidades diferentes, dificultam a aproximação em uma perspectiva mais interativa de estudantes e professores, que Madeira (2010) adverte, deve ser tratada com parcimônia. Assim, observa-se que, como destacam Tardif e Lessard (2008, p. 112), “[...], a docência é um trabalho de limites imprecisos e variáveis entre os indivíduos e as circunstâncias."

O segundo fator "Competência Profissional" captou a valorização da formação profissional por parte do estudante e o conhecimento técnico necessário ao exercício da profissão. Nesse contexto, o fator exprimiu a operacionalização prática de conceitos teóricos típicos do cotidiano profissional, associado a aspectos didáticos do professor, este entendido como a capacidade de ensinar (PIMENTA, 2012), representada pela clareza na exposição dos conteúdos, para assim contribuir para que os estudantes elaborem suas próprias construções teóricas dos conceitos estudados. Nessa perspectiva, destaca-se a dimensão técnica e profissional do professor, reconhecida como elemento fundamental para "dominar o conteúdo" (PACHANE, 2012) e assim possibilitar interpretá-lo, posicioná-lo histórica e socialmente, instrumentalizá-lo e torná-lo sistematizado. Conferindo, então, cientificidade e possibilitando distinguir a essência da aparência, a teoria da prática, para possibilitar a formação profissional do estudante (CUNHA, 2017).

Referido fator também captou a valorização do estudante por seu futuro profissional e insere o professor no processo como aquele que, mais experiente, se posiciona como mediador da formação do estudante (LIBÂNEO, 2013). A amplitude da ação universitária como instituição exprime esse, entre outros desafios, com os quais seus integrantes devem lidar, que, segundo Pimenta e Anastasiou (2014, p. 163), consiste na “[...] preparação para o exercício de atividades profissionais que exijam a aplicação de conhecimentos e métodos científicos." Dessa forma, esse fator sintetizou a competência do professor no domínio da profissão e na capacidade de mediar a formação profissional do estudante, aspectos observados também nas investigações de Cândido et al. (2014). 
O terceiro fator "Competência Técnica do Ensino" captou a sistematização do conteúdo da disciplina, organização na condução das aulas, preparação adequada do material didático e, nessa perspectiva, Libâneo (2010) reforça essa ação deliberada do professor na preparação da disciplina, que se estende desde a explicitação dos objetivos, até a seleção e organização de conteúdos, escolha da metodologia e se constitui da compreensão da capacidade cognitiva do estudante. Nesse processo, que ultrapassa a sala de aula em si, há a presença da intencionalidade deliberada para desencadear a ação de aprender (PIMENTA; ANASTASIOU, 2014). Na mesma perspectiva, Araújo (2001, p.13) define a dimensão técnica do ensino como "técnica, método, metodologia, processo, procedimento, estratégia, tática, recurso, instrumento, atividade" e sintetiza ao afirmar que eles ocupam um lugar necessário como prática pedagógica.

Madeira (2010), ao discorrer sobre o planejamento de ensino, reforça sua necessidade do conteúdo (o que ensinar) e da estratégia (como ensinar), estabelecidos a priori e constituídos com base em um processo mental do que se espera que aconteça ao longo da disciplina, classificando-o como um guia, uma carta de intenções, um conjunto de decisões preparatórias para ministrar a disciplina que, apesar de flexível, evita a improvisação e o amadorismo, devendo ser capaz de representar uma fração do projeto político-pedagógico do curso, atendendo às diretrizes curriculares. Nesse sentido, o fator em essência exprime que esses aspectos são claramente percebidos e valorizados pelos estudantes.

O quarto fator "Competência Tecnológica" captou o uso da tecnologia no processo de comunicação e como instrumento de aprendizado pelos estudantes. Explicitado na utilização do e-mail e pela indicação de sites para pesquisa, incluindo artigos e material para leitura e aprofundamento, ele revela o cotidiano dessa geração na utilização de tecnologias e na interconectividade. Nessa perspectiva, os nativos da Geração Y são os primeiros a conviver, desde seu nascimento, com a aceleração da tecnologia. Essa perspectiva foi captada por Libâneo (2010) e Madeira (2010), que reforçam a necessidade de incorporá-la à perspectiva educa- cional. Destacada como uma das principais características dessa geração, os nativos da Geração Y, diferentemente de seus professores, na maioria da Geração X, não precisaram aprender a utilizar as máquinas, uma vez que acompanharam a evolução tecnológica nos últimos anos (LANCASTER; STILLMAN, 2011).

Tendo como referência a identificação dos fatores, foi utilizada a análise de cluster para classificar os estudantes e compreender como eles valorizam as competências dos professores. O método para a formação dos clusters foi o hierárquico aglomerativo, que adotou como medida de similaridade o algoritmo de Ward, calculado pela distância Euclidiana. O algoritmo de Ward foi selecionado por sua capacidade privilegiada de formar clusters com tamanhos os mais semelhantes possíveis entre si (HAIR et al., 2009).

Os clusters foram formados pelos escores fatoriais, calculados pelo método da regressão. Os escores fatoriais representam a posição relativa dos estudantes na avaliação geral dos fatores. Destaca-se que os escores fatoriais, quando calculados para todos os fatores e independentemente dos clusters, apresentam média zero $(0,00)$ e desvio padrão um $(1,00)$. Assim, quanto mais a média do cluster se afastar de zero $(0,00)$, maior será a necessidade da competência (se assumir sinal positivo), ou ao contrário, se a competência não for considerada necessária (assumirá sinal negativo). Nos casos em que o desvio padrão for menor que a unidade $(1,00)$, mais próximo da média se concentrarão os escores fatoriais, da mesma forma, quando o desvio padrão for maior que a unidade $(1,000)$, mais dispersos estarão esses valores.

A interpretação dos clusters levou em conta os valores das médias e dos desvios padrão dos escores fatoriais. Assim, escores próximos a zero $(0,000)$ indicam valores médios para a necessidade da competência: entre 0,00 e 0,49 (com sinais positivos ou negativos) foram considerados baixos, entre $0,50 \mathrm{e}$ 1,00 , intermediários e acima de 1,00, altos. Quanto ao desvio padrão, nos casos em que ele foi menor que a unidade $(<1,00)$, foi considerado baixo, e maior que a unidade $(>1,00)$, foi interpretado como alto. $\mathrm{O}$ desvio padrão foi utilizado para avaliar a dispersão dos escores em torno do escore médio do cluster. 
O número de clusters foi determinado pela "regra da parada". Esse procedimento, como recomendam Hair et al. (2009) e Fávero et al. (2009), ocorre pelas medidas de similaridades. Assim, "no momento em que ocorre um aumento desproporcional nos coeficientes de proximidade, deve-se selecionar a quantidade de agrupamentos imediatamente anterior, e assim define-se o número indicado de grupos a serem estudados.” (MATTOS; SANTANA, 2014, p. 65). Neste estudo, a aplicação dessa regra resultou em cinco clusters (Tabela 3).

Tabela 3 - Caracterização dos clusters

\begin{tabular}{|c|c|c|c|c|c|c|c|c|c|c|c|c|c|c|}
\hline \multirow[t]{2}{*}{ Clusters } & \multicolumn{2}{|c|}{ Quant. } & \multicolumn{3}{|c|}{$\begin{array}{l}\text { Competência } \\
\text { Interpessoal }\end{array}$} & \multicolumn{3}{|c|}{$\begin{array}{l}\text { Competência } \\
\text { Profissional }\end{array}$} & \multicolumn{3}{|c|}{$\begin{array}{c}\text { Competência } \\
\text { Técnicas de Ensino }\end{array}$} & \multicolumn{3}{|c|}{$\begin{array}{l}\text { Competência } \\
\text { Tecnológica }\end{array}$} \\
\hline & Freq. & $\%$ & éd. & DP & Aval. & réd. & DP & Aval. & Iéd. & DP & Aval. & Iéd. & DP & Aval. \\
\hline An & 210 & 100 & 0,00 & 1,00 & $\odot$ & 0,00 & 1,00 & $\odot$ & 0,00 & 1,00 & $\odot$ & 0,00 & 1, & 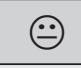 \\
\hline $\mathrm{Clu}$ & 40 & 19 & 021 & 1,00 & $\odot$ & 051 & 0,28 & (:) & 0,53 & 04 & ;) & $-1,10$ & 1, & : \\
\hline $\mathrm{Clu}$ & 65 & 31 & 045 & 0 & $\odot$ & 33 & $0 ?$ & $\odot$ & 0,50 & 0,2 & ;: & 0,65 & 0 , & (;) \\
\hline $\mathrm{Cl}$ & 38 & 18 &, 11 & 0,72 & $\odot$ &, 50 & 1,33 & : & 0,01 & 0, & $\odot$ & 0,13 & & :- \\
\hline $\mathrm{Clu}$ & 38 & 18 & 0 & & $\odot$ & 0,25 & & $\odot$ & -1 & & 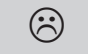 & $D_{0}$ & 0,97 & \%: \\
\hline Cluster 5 & 29 & 14 & 1,64 & 0,86 & : & 0,19 & 0,57 & $\odot$ & $-0,15$ & 1,02 & ; & $-0,04$ & 0,84 & 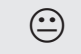 \\
\hline
\end{tabular}

Fonte: pesquisa de campo.

Os clusters foram testados com o teste paramétrico One-Way Anova para identificar os fatores que mais diferenciaram os clusters. O resultado do teste revelou que a "Competência Profissional" $(\mathrm{F}=53,947$; sig. $=0,00)$ foi o principal diferenciador dos grupos, seguida da "Competência Interpessoal" ( $\mathrm{F}=45,993$; sig. $=0,00)$, "Competência de Técnicas de Ensino" ( $F=40,652$; sig. $=0,00)$ e "Competência Tecnológica" $(\mathrm{F}=29,983$; sig. $=0,00)$.

Quanto às características dos clusters, o primeiro (Cluster 1) foi formado por 19\% (40) dos estudantes e posicionou-se conforme a média $(0,00 \pm 1,00)$ quanto à "Competência Interpessoal" dos professores $(0,21 \pm 1,00)$. Contudo, esse cluster mostrou valorizar de forma diferenciada a "Competência profissional" $(0,51 \pm 0,28)$ e a "Competência Técnica de Ensino" $(0,53 \pm 0,45)$ dos professores. Já com relação à "Competência Tecnológica" $(-1,10 \pm 1,10)$, esse grupo de estudantes não considerou essa competência importante para seus professores. Dessa forma, a característica marcante desse grupo foi valorizar aspectos técnicos da profissão ensinados com metodologias de ensino adequadas.
O segundo cluster (Cluster 2) foi o que reuniu a maior parte dos estudantes, com $31 \%$ (65) dos participantes posicionados nesse agrupamento. A principal característica do cluster foi comportar-se conforme a média para a "Competência Interpessoal" $(0,45 \pm 0,53)$ e "Competência Profissional" $(0,33 \pm 028)$ e valorizar de forma superior a "Competência Técnica de Ensino" $(0,50 \pm 0,23)$ e a “Competência Tecnológica" $(0,65 \pm 0,36)$. Assim, esse grupo valoriza aulas planejadas, bem estruturadas e com o emprego de recursos tecnológicos.

O terceiro cluster (Cluster 3) foi composto por $18 \%$ (38) dos estudantes que mostram comportamento conforme a média para três das quatro competências identificadas como necessárias aos professores, foram elas: a "Competência Interpessoal" $(-0,11 \pm 0,72)$, a "Competência Técnicas de Ensino" $(0,01 \pm 0,93)$ e a "Competência Tecnológica" $(0,13 \pm 0,77)$. Contudo, esse agrupamento não considerou que a "Competência Profissional" $(-1,50 \pm 1,33)$ fosse um elemento distintivo do professor. Nesse contexto, esse agrupamento deseja professores capazes de desenvolver bons relacionamentos, 
utilizar bem as metodologias de ensino em aulas planejadas e bem articuladas e empregar tecnologias nas aulas e na comunicação com os estudantes.

O quarto cluster (Cluster 4) foi formado por $18 \%$ (38) dos estudantes que avaliam conforme a média a "Competência Interpessoal" $(0,36 \pm 0,59)$, a "Competência Profissional" $(0,25 \pm 0,51)$ e a "Competência Tecnológica" $(-0,06 \pm 0,97)$ dos professores. Entretanto, esses estudantes evidenciaram que não valorizam a "Competência Técnicas de Ensino" (-1,30 $\pm 1,10)$. Considerando esse comportamento, observa-se que uma parte dos estudantes valoriza os relacionamentos com professores experientes profissionalmente, que têm habilidade para transmitir sua experiência na sala de aula e que empregam tecnologia para mediar o aprendizado e a comunicação, mas, que, não necessariamente, precisam utilizar as técnicas e metodologias de ensino para atuar na profissão.

O quinto cluster (Cluster 5), com 14\% (29) dos estudantes posicionados nesse estrato, reuniu aqueles que avaliaram em torno da média a "Competência Profissional" $(0,19 \pm 0,57)$, a "Competência de Técnica de Ensino" $(-0,15 \pm 1,02)$ e a "Competência Tecnológica" $(-0,04 \pm 0,84)$. Esse grupo discordou da necessidade de "Competências Interpessoais" $(-1,64 \pm 0,86)$ para os professores, revelando um grupo de estudantes que avaliam necessárias as competências identificadas na pesquisa. Entretanto, não consideram a necessidade da receptividade dos professores, sugerindo autonomia e impessoalidade na relação com os professores.

\section{CONSIDERAÇÕES FINAIS}

Esta pesquisa possibilitou identificar as competências docentes mais valorizadas pelos estudantes de Administração, pertencentes à Geração Y. Foram identificados quatro fatores, que explicaram $67,12 \%$ da variância dos dados e apresentaram elevada consistência interna. Foram eles: competências interpessoais, competências profissionais, competências técnicas de ensino e competências tecnológicas. Com base na análise descritiva dos dados, observou-se que os entrevistados consideraram todas as variáveis investigadas como necessárias ao processo de ensino e aprendi- zagem, com destaque para a capacidade de saber ensinar, ter domínio do conteúdo, estabelecer relação entre teoria e prática e despertar o interesse do aluno pelo conteúdo, além de características como ser claro nas explicações, preparar bem o material utilizado e vir preparado para as aulas.

Por outro lado, a classificação dos estudantes, pela técnica de análise de clusters, resultou em cinco agrupamentos, com destaque para o que reuniu a maior parte dos entrevistados, o Cluster 2 , que reuniu os estudantes que valorizam mais as competências técnicas de ensino e tecnológicas. Os resultados obtidos podem servir de base tanto para os docentes como para os gestores do ensino de Administração, de modo que, conhecendo os anseios dos estudantes dessa geração, reduzam os gaps de forma a aprimorar o processo de ensino e aprendizagem, tendo em vista a necessidade de formar profissionais qualificados para atender as necessidades das organizações e da sociedade.

Este estudo se baseou na perspectiva discente acerca do tema, o que não finaliza esta discussão. É possível encontrar uma lacuna na literatura no que diz respeito ao papel dos gestores institucionais no processo de desenvolvimento das competências docentes aqui levantadas, o que pode vir a ser objeto de futuras pesquisas. Destaca-se como limitação deste estudo a abrangência da amostra, restrita aos alunos que frequentavam as aulas. Assim, uma parcela considerável de discentes pode não ter sido captada pela investigação.

\section{REFERÊNCIAS}

ALCADIPANI, R.; BRESLER, R. Mcdonaldização do Ensino: universidades e escolas adotam o modelo fast-imbecilização. Carta Capital, v. 6, n. 122 , p. 20-24, 10 maio 2000.

AMARO, R. A. Da qualificação à competência: deslocamento conceitual e individualização do trabalhador. RAM, São Paulo, v. 9, n. 7, p. 89-111, nov./set. 2008.

AMUI, A. M. Alinhamento: o caminho para garantir a empregabilidade da geração Y. Revista da ESPM, v. 18, n. 3, p. 74-80, maio/ jun. 2011. 
ARAÚJO, J. C. A. Para uma análise das representações sobre as técnicas de ensino. In: VEIGA, I. P. A. (org.) Técnicas de Ensino: por que não? Campinas: Papirus, 2001.

BARNEY, J. B.; HESTERLY, W. S. Administração estratégica e vantagem competitiva. São Paulo: Pearson Prentice Hall, 2007.

BONOTTO, F.; BITENCOURT, C. C. Os Elementos das Competências em Grupos de Trabalho - a Experiência do COPESUL. In: ENCONTRO DA ASSOCIAÇÃO NACIONAL DE PÓS-GRADUAÇÃO E PESQUISA EM ADMINISTRAÇÃO, 30., 2006, Salvador, 2006. Anais [...]. Brasília: Anpad, 2006.

BRUNO-FARIA, M.; BRANDÃO, H. P. Competências Relevantes a Profissionais da Área de T\&D de uma Organização Pública do Distrito Federal. Revista de Administração Contemporânea, Curitiba, v. 4, n. 1, p. 161-176, jul./set. 2003.

CANDIDO, C. M. et al. A representação social do "bom professor" no ensino superior. Psicologia e Sociedade, Belo Horizonte, v. 26, n. 2, p. 356-365, 2014.

CARDOSO, A. L. J. Percepções de gestores sobre competências gerenciais em diferentes contextos: estabilidade e mudança organizacional. REBRAE, Curitiba, v. 2, n. 2, p. 147- 69, maio/ago. 2009.

CHAUI, M. S. A filosofia como vocação para a liberdade. Estudos Avançados, São Paulo, v. 17, n. 49, p. 7-15, set./dez. 2003.

CLOSS, L. Q.; ARAMBURU, J. V.; ANTUNES, E. D. D. GESTÃA.org, Recife, v. 7, n. 2, p. 150169, maio/ago. 2009.

COSTA, F. J. Mensuração e desenvolvimento de escalas. Rio de Janeiro: Ciência Moderna, 2011.

CUNHA, M. I. O bom professor e sua prática. São Paulo: Papirus Editora, 2017.
DIAS JÚNIOR, C. M. et al. Desenvolvimento de competência do administrador: um estudo em ambiente simulado. Revista de Ciências da Administração, Florianópolis, v. 16, n. 38, p. 172-182, abr. 2014.

DUTRA, J. S.; HIPÓLITO, J. A. M.; SILVA, C. M. Gestão de pessoas por competência: o caso de uma empresa do setor de telecomunicações. Revista de Administração Contemporânea, Maringá, v. 4, n. 1, p. 161-176, jan./abr. 2000.

FÁVERO, L. P. et al. Análise de dados: modelagem multivariada para a tomada de decisão. Rio de Janeiro: Elsevier, 2009.

FLEURY, M. T. L; FLEURY, A. Construindo o Conceito de Competência. Revista de Administração Contemporânea, Maringá, v. 5, p. 183196, 2001.

GOMES, E. M.; MORGADO, A. Compêndio de administração. Rio de janeiro: Elsevier, 2012.

GRIMAND, A. Das competências individuais às competências estratégicas: uma experiência de modelagem das estratégias concorrenciais com base na gestão de recursos humanos. In: RETOUR, D. et al. Competências coletivas: no limiar da estratégia. São Paulo: Artmed, 2011.

GUEDES, K. L.; ANDRADE, R. O. B; NICOLINI, A. M. A avaliação de estudantes e professores sobre a experiência com a aprendizagem baseada em problemas. Administração Ensino e Pesquisa, São Paulo, v. 16, n. 1, p. 71-100, jan./mar. 2015.

GUELFI, B. F. C. et al. Características do bom professor sob a ótica dos discentes de ciências contábeis da Geração Y. In: CONGRESSO ASSOCIAÇÃO NACIONAL DE PÓS-GRADUAÇÃO EM CONTABILIDADE, 9., 2015, Curitiba. Anais [...]. São Paulo: Anpcont, 2015.

HAIR JUNIOR, J. F. et al. Análise multivariada de dados. São Paulo: Bookman, 2009. 
HANASHIRO, D. M. M.; NASSIF, V. M. J. Competências de Professores: um fator competitivo. Revista Brasileira de Gestão de Negócios, São Paulo, v. 8, n. 20, p. 45-56, jan. /abr. 2006.

HILL, M. M.; HILL, A. Investigação por questionário. Lisboa: Silabo, 2012.

KARAWEJCZYK; T. C.; ESTIVALETE, V. Professor universitário: o sentido do seu trabalho e o desenvolvimento de novas competências em um mundo em transformação. In: ENCONTRO DA ASSOCIAÇÃO NACIONAL DE PÓS-GRADUAÇÃO E PESQUISA EM ADMINISTRAÇÃO, 27., 2003, Atibaia. Anais [...]. Brasília: Anpad, 2003.

KLINE, R. B. Principles and practice of structural equation modeling. New York: The Guilford Press, 1998.

LANCASTER, L. C.; STILLMAN, D. O Y da questão: como a geração Y está transformando o mercado de trabalho. São Paulo: Saraiva, 2011.

LIBÂNEO, J. C. Didática. São Paulo: Cortez, 2013.

LIBÂNEO, L. C. Adeus professor, adeus professora. São Paulo: Cortez, 2010.

LOMBARDIA, P. G. Quem é a geração Y. HSM Management, n. 70, p. 1-7, set./out. 2008.

MADEIRA, M. C. Sou professor universitário: e agora? São Paulo: Sarvier, 2010.

MARIN, T. I. S.; LIMA, S. J.; CASA NOVA, S. P. C. Formação do contador: o que o mercado quer, e o que ele tem? Estudo de caso sobre o perfil do profissional dos alunos de contabilidade. In: $\mathrm{CON}-$ GRESSO USP DE CONTROLADORA E CONTABILIDADE, 11., 2011, São Paulo. Anais [...]. São Paulo: USP, 2011.

MARTINS, G. A.; THEÓPHILO, C. R. Metodologia da investigação científica para ciências para Ciências Sociais Aplicadas. São Paulo: Atlas, 2009.
MARTINS, K.; RAUSCH, R.B. Saberes do bom professor universitário na percepção de acadêmicos concluintes da graduação. Revista Intersaberes, Curitiba, v. 7, n. 14, p. 246-261, ago./dez. 2012.

MASETTO, M. T. Competência pedagógica do professor universitário. São Paulo: Summus Editorial, 2003.

MATTOS, C. A. C.; SANTANA, A. C. As contribuições da pecuária leiteira para agricultores familiares: um estudo no sudeste do estado do Pará Extensão Rural, Santa Maria, v. 20, n. 1. p. 56-71 jan./mar. 2014.

MICHAUX, V. Articular as competências individual, coletiva e estratégica: esclarecendo a teoria dos recursos e do capital social. In: RETOUR, D. et al. Competências coletivas: no limiar da estratégia. São Paulo: Artmed, 2011.

MULLER, J.; DEWES, F. O impacto da inserção da geração Y no mercado de trabalho. Universo Acadêmico, Niterói, v. 5, n. 1, jan./dez. 2012.

NOGUEIRA, A. J. F. M.; BASTOS, F. C. Formação em administração: o gap de competências entre alunos e professores. REGE, São Paulo, v. 19, n. 2, p. 223-240, abr./jun. 2012.

NOGUEIRA, D. R.; CASA NOVA, S. P. C.; CARVALHO, R. C. O. O bom professor na perspectiva da geração Y: uma análise sob a percepção dos discentes de Ciências Contábeis. Enfoque Reflexão Contábil, Maringá, v. 31, n. 3, p. 37-52, set./dez. 2012.

NÓVOA, A. Professores: imagens do futuro presente. Lisboa: Educa, 2009.

ORO, I. M.; SANTANA, A. G.; RAUSCH, R. B. Os saberes do "bom professor" de ciências contábeis na compreensão de acadêmicos da Geração Y. In: ENCONTRO DE ENSINO E PESQUISA EM ADMINISTRAÇÃO E CONTABILIDADE, 4., 2013, Brasília. Anais [...]. Brasília: Anpad, 2013. 
PACHANE, G. G. Quem é seu melhor professor universitário e por quê? Características do bom professor universitário sob o olhar de licenciados. Educação, Santa Maria, v. 37, n. 2, p. 307-320, maio/ago. 2012.

PAIVA, K. C. M.; MELO, M. C. O. L. Competências profissionais docentes e sua gestão em Universidades Mineiras. In: ENCONTRO DE GESTÃO DE PESSOAS E RELAÇÕES DE TRABALHO, 2., 2009, Curitiba. Anais [...]. Brasília: Anpad, 2009.

PESTANA, M. H.; GAGEIRO, J. N. Análise de dados para ciências sociais: a complementariedade do SPSS. Lisboa: Silabo, 2008.

PICCHIAI, D. Estratégia, estrutura e competências gerenciais: estudo de uma operadora de plano de saúde, modalidade autogestão. Revista de Ciências da Administração, Florianópolis, v. 11, n. 25, p. 229-253, set./dez. 2009.

PIMENTA, S. G. Formação de professores: identidade e saberes da docência. In: PIMENTA, S. G. (org.). Saberes pedagógicos e atividade docente. São Paulo Cortez, 2012.

PIMENTA. S. G.; ANASTASIOU, L. G. C. Docência no ensino superior. São Paulo: Cortez, 2014.

PINHEL, I.; KURCGANT, P. Reflexões sobre competência docente no ensino de enfermagem. Revista da escola de Enfermagem da USP, São Paulo, n. 4, v. 41, p. 711-716, out./dez. 2007.

PLUTARCO, F. F.; GRADVOHL, R. F. Competências dos professores de administração: a visão dos alunos do curso de graduação. In: ENCONTRO DA ASSOCIAÇÃO NACIONAL DE PÓS-GRADUAÇÃO E PESQUISA EM ADMINISTRAÇÃO, 34., 2010, Rio de Janeiro. Anais [...]. Brasília: Anpad, 2010.

RUAS, R. Gestão por competências: uma contribuição à das organizações. In: Ruas, R.; ANTONELLO, C.; BOFF, L. H. Aprendizagem organizacional e competências. Porto Alegre: Bookman, 2005.
SANTOS, K. C. G. O estágio docente e o desenvolvimento de competências: um estudo no programa de pós-graduação em administração da Universidade Federal da Paraíba. 2013. 100 f. Dissertação (Mestrado em Administração) - Centro de Ciências Sociais Aplicadas, Universidade Federal da Paraíba, João Pessoa, 2013.

SILVA, F. M. O que Sabemos sobre Competências coletivas? In: ENCONTRO DA ASSOCIAÇÃO NACIONAL DE PÓS-GRADUAÇÃO E PESQUISA EM ADMINISTRAÇÃO, 34., 2012, Rio de Janeiro. Anais [...]. Brasília: Anpad, 2012.

SOUZA, D. L.; ZAMBALDE, A. L. Desenvolvimento de competências e ambiente acadêmicos: um estudo em cursos de administração de Minas Gerais. Revista de Administração, São Paulo, v. 50, n. 3, p. 338-352, jul./set. 2015.

TARDIF, M.; LESSARD. C. O Ofício do Professor. Petrópolis: Vozes, 2008.

ZARAFIAN, P. O modelo da competência. São Paulo: Senac, 2003. 